\title{
Erratum to: Usability study of a simplified electroencephalograph as a health-care system
}

Shinichi Motomura ${ }^{1 *}$, Muneaki Ohshima ${ }^{2}$ and Ning Zhong ${ }^{1}$

\section{Erratum to: Health Inf Sci Syst (2015) 3:4 DOI 10.1186/s13755-015-0012-z}

After the publication of this work [1], we noticed an error whereby Figure 7 had five charts representing data from different subject areas which are identical. The corrected Fig. 7 is given below: 


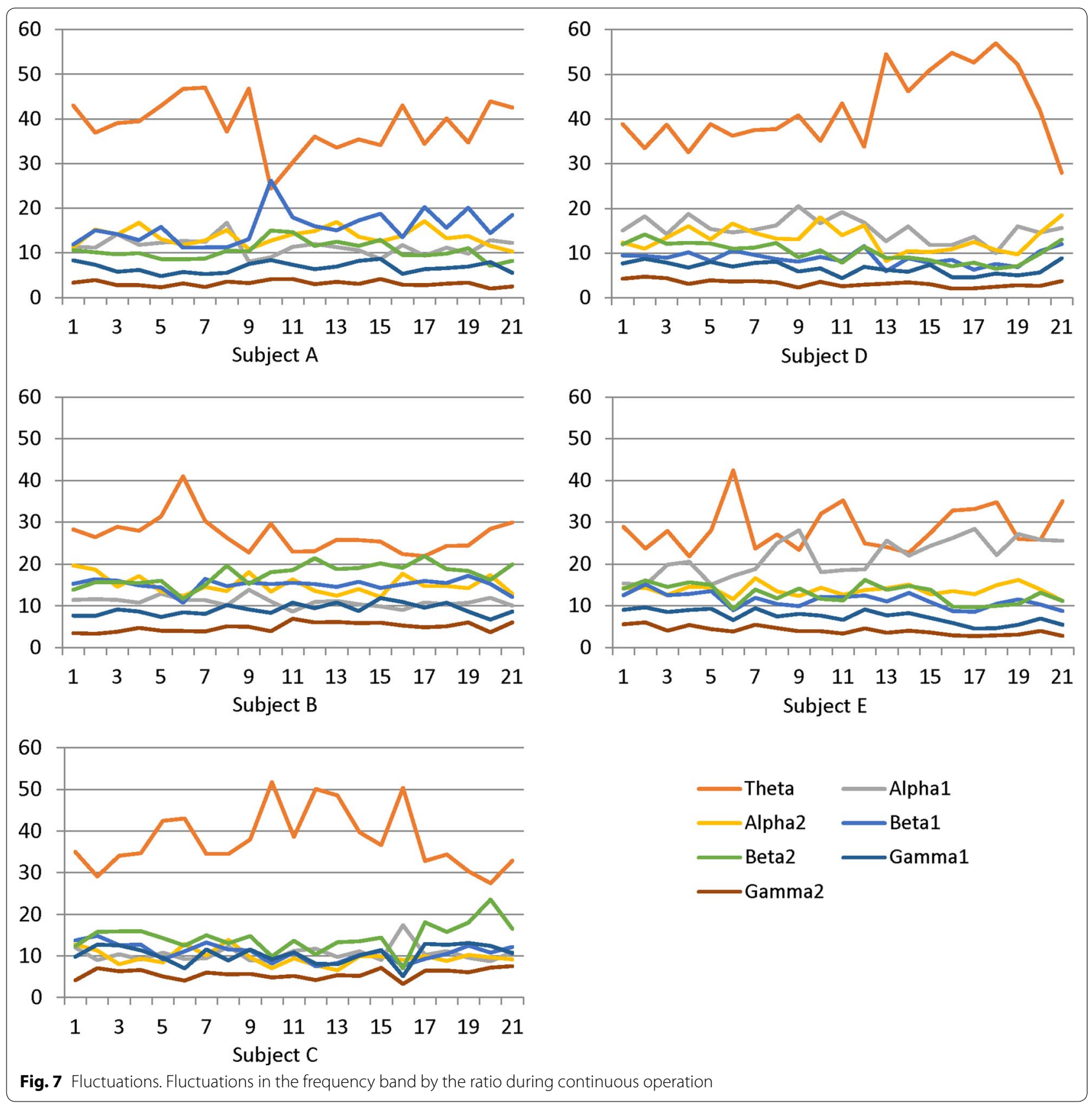

Author details

${ }^{1}$ Maebashi Institute of Technology, Kamisadori 460-1, Maebashi, Japan. ${ }^{2}$ Ikuei Junior College, Takasaki, Japan.
Received: 5 January 2016 Accepted: 5 January 2016 Published online: 16 February 2016

\section{Reference}

1. Motomura S, Ohshima M, Zhong N. Usability study of a simplified electroencephalograph as a health-care system. Health Inf Sci Syst. 2015;3:4. 